\title{
Desafios e possibilidades do Programa Bolsa Família: houve mudanças nas condições de vida de seus beneficiários?
}

\author{
Challenges and possibilities of the Bolsa Familia Program: have there been changes in the \\ living conditions of your beneficiaries?
}

\author{
Poliana Aparecida de Arruda* \\ Zélia Zilda Lourenço de Camargo Bittencourt ${ }^{* *}$
}

\begin{abstract}
Resumo
O Bolsa Família é o principal programa de transferência condicionada de renda do Brasil no combate à fome e à miséria. $\mathrm{O}$ objetivo deste artigo foi identificar, sob o olhar dos beneficiários, as mudanças que o Programa Bolsa Família ocasionou em suas condições de vida. O estudo exploratório de orientação qualitativa entrevistou 16 beneficiários do programa. Todos os participantes eram mulheres, a maioria casada ou em união estável, baixa escolaridade, sem vínculo empregatício, sendo em grande parte a responsável pela unidade familiar. O Programa Bolsa Família foi considerado "ajuda" e não um direito viabilizado por política pública, enquanto o benefício "um complemento da renda para a alimentação". O Programa não possibilitou acesso ao mercado de trabalho, evidenciando a necessidade de políticas públicas articuladas e ações coerentes com o perfil dos beneficiários e da realidade local para o enfrentamento das diversas vulnerabilidades.
\end{abstract}

Palavras-chave: Programa Bolsa Família. Política pública. Condições de vida. Vulnerabilidade Social. Família.

\begin{abstract}
The Bolsa Familia is the main program of conditional transfer of income from Brazil in the fight against hunger and misery. The purpose of this article was to identify under the look of the beneficiaries the changes that the bolsa familia program brought into their living condition. The exploratory study of qualitative guidance was attended by 16 beneficiaries of the programme, which were interviewed. All the beneficiaries were women, mostly married or in stable union, low schooling, no employment relationship, most responsible for the family unit. The Bolsa Familia program was considered as "aid" and not entitlement made possible by public policy. They considered the benefit a "supplement to the income for food". The programme did not facilitate access to the labour market and the promotion of citizenship, highlighting the need for articulated public policies and actions consistent with the profile of the beneficiaries and the local reality for the confrontation of the various vulnerabilities.
\end{abstract}

Keywords: Bolsa Familia program. Public policy. Living conditions. Social vulnerability. Family.

\footnotetext{
* Assistente Social pela Universidade de Ribeirão Preto. Mestre em Saúde, Interdisciplinaridade e Reabilitação pela UNICAMP.

${ }^{* *}$ Assistente Social graduada pela PUC de Campinas, Mestrado e Doutorado em Saúde Coletiva pela UNICAMP. Docente no curso de Fonoaudiologia e do Programa de Pós-Graduação Saúde, Interdisciplinaridade e Reabilitação da FCM/UNICAMP.
} 


\section{Introdução}

Para minimizar as crescentes desigualdades sociais no Brasil, o governo federal criou em 2003 um programa de transferência direta de renda às famílias pobres e extremamente pobres $^{1}$, denominado Programa Bolsa Família (SILVA; LIMA, 2014, p. 30). Este Programa tem como sustentação ideológica três eixos elementares: transferência de renda, o acesso aos direitos por meio das condicionalidades e a articulação com outras ações, visando a integração de várias políticas sociais a fim de estimular o desenvolvimento e a emancipação das famílias (SANTOS et al., 2014, p. 1386).

Tem sido considerado uma "porta de entrada" para um conjunto de políticas sociais como saúde, educação e assistência social, propiciando o acesso à cidadania através de uma transferência de renda, mediante "condicionalidades" para a permanência no programa. Tais condicionalidades, na área da saúde, dizem respeito à exigência de acompanhamento pré e pós-natal, nutricional e vacinação das crianças. Na área da educação, é exigida frequência escolar mínima de 85\% para crianças entre 6 e 15 anos e de $75 \%$ para jovens entre 16 e 17 anos.

As condicionalidades se referem aos compromissos que essas famílias devem assumir para se manterem no programa. Segundo Neri (2013, p. 126), tais benefícios e suas condicionalidades, ou seja, os compromissos que as famílias devem atender em relação ao programa, deixam as pessoas menos pobres no presente e buscam reduzir a pobreza no futuro.

O programa Bolsa família-PBF, surgiu com o objetivo central de combater a pobreza e a desigualdade no Brasil, e promover o acesso das famílias aos direitos sociais básicos e romper com o ciclo intergeracional da pobreza (BRASIL, 2015).

No escopo do programa a condicionalidade surge como um mecanismo de garantia de acesso aos direitos sociais básicos necessários para compor uma base de inclusão. Porém, para que essa inclusão ocorra, é necessário um arranjo complexo de vários fatores, visto que a pobreza é resultado não só da ausência de renda, mas de determinantes psicossociais, culturais, econômicos e geográficos. Assim a oferta pública de serviços deve se aproximar das famílias constituindo um sistema articulado, ativo e com qualidade para cumprir sua função.

\footnotetext{
${ }^{1}$ No momento da realização da pesquisa para efeitos do PBF era considerado pobre a família que tinha renda per capita de 70,00 a 140,00 e extremamente pobres com renda mensal per capita de até R\$ 70,00 (BRASIL, 2012).
} 
Para Silva (2016), as condicionalidades, no entanto, constituem estruturas fundamentais de articulação dos serviços. Atualmente, o que se observa é uma carência desta articulação no trato das políticas públicas.

Importante considerar que muitos debates relacionados às condicionalidades suscitam questões polêmicas. De acordo com Bueno (2009), os programas condicionados podem ter uma visão negativa pelo fato de estarem atrelados aos serviços públicos precários, o que evidencia uma inversão de responsabilidades: enquanto os pobres devem prestar conta de suas carências, procurando resolvê-las para que acesse um direito, os governos não cumprem com suas obrigações no que diz respeito à oferta de serviços públicos universais e de qualidade (BUENO, 2009).

Por outro lado, pode-se refletir positivamente sobre as condicionalidades, uma vez que não existe hoje o amparo do Estado em situações de risco pessoal ou social da família, podendo inferir que através desses programas há de certa forma, uma ampliação de acesso dos usuários a esses direitos. Nesse sentido, dados da literatura (ÁVILA, 2013, p. 108; SENNA, et al., 2007) sugerem que as condicionalidades possibilitam, de forma intersetorial, "o acesso da população pobre aos serviços sociais básicos, favorecendo a interrupção do ciclo geracional da pobreza", configurando-se dessa maneira, como "promoção a cidadania" no programa. De acordo com Passos (2017, p. 88), programas de transferência de renda:

[...] apoiados nas áreas de saúde e educação têm potencial para combater a pobreza em suas causas e resultados, sendo preciso desenvolver a vertente estrutural, de forma a impactar significantemente no capital humano dos beneficiários e reduzir a pobreza intergeracional. Se as "contrapartidas", forem mais um compromisso do Estado na promoção dos direitos universais do que um dever moral das famílias, forte é a potencialidade de promover equidade e cidadania.

Ainda segundo a autora, "criar uma imagem do programa de garantia de renda com oportunidades para uma vida melhor seria uma tentativa de gerar aceitação social de transferência de renda incondicional" (PASSOS, 2017, p. 88). Passado mais de uma década do Bolsa família, ainda é marcante a pobreza intergeracional, demonstrando o tímido investimento feito nos componentes estruturais dessas condicionalidades.

Importante notar que o descumprimento das condicionalidades está sujeito aos regulamentos gradativos, podendo variar de advertência, bloqueio, suspensão ou cancelamento do benefício, até o desligamento das famílias beneficiárias (BRASIL, 2015). Todos esses aspectos representam uma dimensão fundamental no desenho do programa. 
É imprescindível destacar que a inclusão das famílias em programas sociais depende de critérios de cada programa, analisados no momento de sua inscrição no Cadastro Único, "que identifica e caracterizam as famílias em situação de extrema pobreza ou de pobreza, segundo os níveis de renda familiar per capita" (SANTOS; MAGALHÃES, 2012, p. 1216).

A despeito do programa incentivar e tornar compulsória a frequência de crianças e jovens à escola, observa-se que ainda não se atinge a cobertura integral, (PASSOS, 2017, p. 94). Todavia, houve um importante progresso: "entre 2005 e 2009 no tocante à cobertura de vacinação entre os beneficiários, que saltou de $79 \%$ para $82 \%$, além da redução da mortalidade infantil por desnutrição e doenças a ela associadas ter caído 58\%" (SOUSA; BRITO, 2015, p. 6).

Dentre as crianças acompanhadas na área da saúde "no ano de 2012, cerca de 99,2\% encontravam-se com calendário de vacinação em dia, e $81 \%$ tiveram seu estado nutricional avaliado. Dentre as gestantes "acompanhadas pelas equipes de saúde, cerca de $99 \%$ estavam com pré-natal em dia", revelando o efeito positivo do programa (MAGALHÃES JÚNIOR; JAIME; LIMA, 2013, p. 104). No município estudado, no tocante às condicionalidades na área da saúde, no ano de 2012 cerca de 1.077 crianças de 0 a 6 anos foram acompanhadas pelas equipes de saúde, correspondendo a $71,89 \%$ dos atendimentos das famílias que recebem o Bolsa Família.

De acordo com especialistas do Ministério do Desenvolvimento Social, a chamada "porta de saída" do programa de transferência de renda ainda é estreita e precisa ser melhor qualificada, devendo resultar em políticas públicas de emprego, de qualificação profissional e de educação (DANTAS apud LIMA, 2013). Neste sentido, é necessário criar estratégias, oportunidades para superar situações de pobreza que possibilitem a emancipação econômica dos mesmos e uma qualidade de vida digna com acesso aos direitos sociais básicos. Importa considerar que as políticas sociais têm o dever de apresentar um tratamento sem distinção, proporcionando, além de uma porta de entrada para a cidadania e para uma vida melhor, também uma oportunidade de promoção para além da condição de vulnerabilidade em que as famílias se encontram.

Diante de todo o contexto, pensando-se nas políticas sociais brasileiras enquanto direito e não benesse e, especificamente, voltando o olhar para o Programa Bolsa Família, é oportuno entender como o mesmo pode refletir na qualidade de vida, no desenvolvimento humano e nas condições e estilo de vida dos beneficiários. 
Rocha et al. (2011, p. 63) afirmam que a falta de condições econômicas relacionadas às condições de saúde "comprovam a má qualidade de vida dos brasileiros, com baixa qualidade nutricional, o não usufruto de uma vida saudável e a baixa perspectiva de vida". Neste sentido, há de se reconhecer que tais aspectos da vida humana dificilmente serão atingidos por uma população mais vulnerável, sendo necessárias ações efetivas de políticas públicas. Diante do exposto, o objetivo deste artigo foi conhecer o olhar dos beneficiários sobre as mudanças nas suas condições de vida após o ingresso no Programa Bolsa Família.

\section{Método}

Esta pesquisa de abordagem qualitativa (MINAYO, 2006), voltou-se para a análise dos significados e sentidos presentes no contexto das relações entre os beneficiários e o Programa Bolsa Família. Trata-se de um recorte de uma dissertação de mestrado intitulada 'Programa Bolsa Família sob o olhar dos beneficiários de um município do interior de São Paulo'.

O cenário da investigação foi o CRAS - Centro de Referência de Assistência SocialZona Leste, no interior do estado de São Paulo, cidade de Mogi Guaçu, sendo que a coleta de dados ocorreu entre outubro de 2015 a junho de 2016, após aprovação pelo Comitê de Ética em Pesquisa da Universidade Estadual de Campinas, respeitando-se a Resolução 466/12 com o Parecer no 1.203.628.

A amostra foi constituída intencionalmente por beneficiários inscritos no Programa Bolsa Família. Neste estudo, utilizou-se também o critério de saturação teórica de dados (FONTANELLA; RICAS; TURATO, 2008), onde o fechamento amostral sobreveio no momento em que os dados apresentaram uma redundância ou repetição, não se justificando persistir na coleta dos mesmos, constituindo, dessa forma, 16 participantes.

Inicialmente realizou-se pesquisa documental (GIL, 2010) em sistemas oficiais relativos à gerência executiva do Programa Bolsa Família e no banco de dados do Cadastro Único. A partir desse levantamento foi realizada consulta à série histórica do ano de 2015, para conhecer a população beneficiária do programa residente no território em questão. Paralelamente, foram efetivados contatos com os beneficiários à medida em que se dirigiam para atendimento no CRAS, convidando-os a participar voluntariamente de uma entrevista. Todos os participantes assinaram o Termo de Consentimento Livre e Esclarecido (TCLE).

Como técnica de coleta de dados foi utilizada uma entrevista com questões semiestruturadas que foram gravadas com a autorização dos participantes. Para o tratamento 
dos dados utilizou-se como referencial teórico a análise de conteúdo temático, que relaciona estruturas semânticas (significantes) com estruturas sociológicas (significados) dos enunciados, articulando os textos descritos com os fatores que determinam suas características psicossociais, contexto cultural e o processo de produção da mensagem (BARDIN, 2010). A partir dos achados foram realizadas leituras flutuantes possibilitando uma aproximação do material coletado, destacando-se trechos mais relevantes e frequentes para a elaboração das categorias temáticas. Realizada a categorização do material coletado, foi iniciada a fase de interpretação dos dados, com base na literatura pesquisada.

\section{Análise de resultados}

Para conhecer a realidade e caracterizar o perfil dos participantes da investigação foi elaborado um quadro, apresentado a seguir:

Quadro 1: Caracterização dos participantes beneficiários

\begin{tabular}{|c|c|c|c|c|c|c|c|c|c|c|c|c|}
\hline $\begin{array}{c}\text { Parti- } \\
\text { cipantt }\end{array}$ & Sexo & $\begin{array}{c}\text { Estado } \\
\text { Civil }\end{array}$ & Idade & $\begin{array}{l}\text { Escola- } \\
\text { ridade }\end{array}$ & Profissão & $\begin{array}{l}\text { Situação } \\
\text { Trabalho }\end{array}$ & $\begin{array}{l}\text { N. } \\
\text { Filhos }\end{array}$ & $\begin{array}{c}\mathrm{N} \\
\text { Pessoas } \\
\text { na casa }\end{array}$ & $\begin{array}{c}\text { Respon- } \\
\text { sável } \\
\text { pela } \\
\text { unidade } \\
\text { familiar }\end{array}$ & $\begin{array}{c}\text { Tempo de } \\
\text { recebimen } \\
\text { to do } \\
\text { beneficio }\end{array}$ & $\begin{array}{c}\text { Renda } \\
\text { Familiar } \\
\text { incluindo o } \\
\text { BF }\end{array}$ & $\begin{array}{c}\text { Valor } \\
\text { recebido } \\
\text { BF }\end{array}$ \\
\hline P1 & F & Solteira & 31 & \begin{tabular}{|c|} 
E.M. \\
Cursandd
\end{tabular} & Faxineira & Autônoma & 2 & 3 & Mulher & 2 anos & RS 600,00 & RS147,00 \\
\hline P2 & F & Solteira & 27 & E.M.C & Faxineira & Autônoma & 2 & 6 & Mulher & 4 anos & RS $1.000,00$ & RS105,00 \\
\hline P3 & $\mathrm{F}$ & Casada & 38 & E.F.I & Do Lar & - & 3 & 5 & Mulher & 12 anos & RS 780,00 & RS 105,00 \\
\hline P4 & F & Casada & 39 & E.F.C & Diarista & Autônoma & 2 & 4 & Mulher & 4 anos & RS 120,00 & RS 120,00 \\
\hline P5 & F & Casada & 34 & E.F.I & Do Lar & - & 4 & 6 & Marido & 12 anos & RS 800,00 & RS 224,00 \\
\hline P6 & F & Viúva & 45 & E.F.I & Lavradora & $\begin{array}{c}\text { Atividade } \\
\text { Sazonal }\end{array}$ & 3 & 4 & Mulher & 19 anos & RS $2.000,00$ & RS 100,00 \\
\hline P7 & F & Casada & 41 & E.M.C & $\begin{array}{l}\text { Operadora } \\
\text { de Caixa }\end{array}$ & $\begin{array}{c}\text { Afastada - } \\
\text { S/R }\end{array}$ & 2 & 4 & Marido & 2 anos & RS 500,00 & RS 70,00 \\
\hline P8 & F & $\begin{array}{c}\text { Divorci- } \\
\text { ada }\end{array}$ & 37 & E.F.I & Faxineira & Autônoma & 2 & 4 & Mulher & 5 anos & RS 500,00 & RS 112,00 \\
\hline P9 & F & $\begin{array}{l}\text { União } \\
\text { estável }\end{array}$ & 35 & E.M.C & Diarista & Autônoma & 3 & 5 & Marido & 12 anos & RS 700,00 & RS 189,00 \\
\hline P10 & F & Viúva & 48 & E.F.I & Garçonete & Autônoma & 3 & 4 & Mulher & 2 anos & RS 800,00 & RS 35,00 \\
\hline Pll & F & $\begin{array}{l}\text { União } \\
\text { estável }\end{array}$ & 35 & E.F.I & Do Lar & - & 3 & 5 & Marido & 15 anos & RS 700,00 & RS 189,00 \\
\hline P12 & F & Solteira & 37 & E.F.I & $\begin{array}{l}\text { Aux. de } \\
\text { Limpeza }\end{array}$ & Autônoma & 2 & 3 & Mulher & 10 anos & RS 880,00 & RS 35,00 \\
\hline P13 & F & Solteira & 48 & E.F.I & Lavradora & $\begin{array}{l}\text { Desem- } \\
\text { pregada }\end{array}$ & 1 & 2 & Mulher & 2 meses & RS 77,00 & RS 77,00 \\
\hline P14 & F & $\begin{array}{l}\text { União } \\
\text { estável }\end{array}$ & 53 & E.F.I & Do Lar & - & 3 & 5 & Marido & 12 anos & RS 800,00 & RS 154,00 \\
\hline P15 & F & $\begin{array}{l}\text { União } \\
\text { estável }\end{array}$ & 33 & E.F.I & Lavradora & $\begin{array}{c}\text { Em ativi- } \\
\text { dade Sazo- } \\
\text { nal }\end{array}$ & 2 & 3 & Mulher & 4 anos & RS 420,00 & RS 147,00 \\
\hline P16 & $\mathrm{F}$ & Casada & 42 & E.F.I & Do Lar & - & 4 & 6 & Marido & 17 anos & RS $1.800,00$ & RS 180,00 \\
\hline
\end{tabular}


*Legenda: P6, P11, P16, recebiam outros PTR antes do PBF.

**A renda declarada pelas famílias pode não conferir com a que consta no Cadastro Único por este ter sido realizado em momento anterior ao da realização da pesquisa.

***E.F.I - Ensino Fundamental Incompleto; E.F.C - Ensino Fundamental Completo; E.M.C - Ensino Médio Completo.

Fonte: elaborado pelo Autor.

Os dados apresentados no quadro 1 revelam o perfil das famílias beneficiárias do Programa, sendo que todos os participantes da amostra eram mulheres e mães, com idades variando de 27 a 53 anos, com média de idade de 39 anos; a maioria era casada ou encontravase em união estável, com baixa escolaridade, sendo predominante o ensino fundamental incompleto, sem vínculo empregatício e realizando atividades informais ou mesmo sazonais na lavoura. Verificou-se também que o número de habitantes por moradia era em média de 4 a 5 pessoas, composta por pai ou padrasto, mãe, filhos, netos, avós e outro parente, e que 10 mulheres eram as responsáveis pela unidade familiar.

No que diz respeito ao tempo de recebimento do benefício, este variou entre 2 meses e 19 anos, sendo que 50\% da amostra estudada já recebia o benefício há mais de 10 anos. Os achados demonstraram que, em sua maioria, a renda familiar não ultrapassa um salário mínimo, mesmo considerando o PBF, corroborando os dados de que o Programa atende famílias de baixa renda. Alguns participantes dessa pesquisa (07) relataram não ter casa própria e, portanto, dependem de aluguel ou ajuda de terceiros. Quanto às condições de trabalho e ao valor recebido pela sua ocupação, analisou-se que o trabalho informal e/ou desemprego afeta a maioria das participantes. Dentre as entrevistadas, somente uma dependia exclusivamente do benefício, sua única fonte de renda.

\section{Família, público alvo do Programa e a questão de gênero}

Sendo a família o foco de atenção das políticas sociais e, especificamente, do PBF, torna-se importante compreender seu significado enquanto instituição social. Embora venham ocorrendo diversas transformações na concepção e na realidade das famílias na atualidade, muitos ainda a entendem como um modelo nuclear orgânico, um grupo de pessoas que habita a mesma casa, ligados por laços de sangue, compartilhando situações comuns e que tem a mulher como mãe no espaço do lar, que cuida da casa e dos filhos, e o pai como principal provedor e chefe de família (SILVA, 2016). Este modelo tradicional, disciplinador é visto como o certo, o desejável, o tipo ideal de família acordada socialmente. Porém, essa realidade vem se transformando com o tempo, configurando-se em vários tipos e novos formatos de família. Szymanski $(2002$, p. 9) afirma que "a família na atualidade é 
constituída por um grupo de indivíduos que, devido à existência de laços afetivos, optam por conviver juntos, com o cuidado mútuo".

De acordo com o perfil das famílias entrevistadas, podem ser identificados diversos tipos e formatos de famílias, e que segundo os autores são "construídas através de uma somatória de experiências e trajetórias particulares, manifestando-se por meio de arranjos diferenciados e peculiares, denotando a impossibilidade de identificá-la como um padrão familiar uniforme e ideal” (ÁLVARES; JOSÉ FILHO, 2008, p. 16). A maioria das beneficiárias relatou ser responsável pela unidade familiar, vivendo em família extensa composta por pais, filhos, netos, enteados, irmãos e outros parentes.

Pensar em famílias do PBF, famílias pobres, é pensar nas fragilidades e privações que são impostas a elas. Silva (2016) entende que tais famílias estão sujeitas à privação de condições propulsoras de desenvolvimento dos seus integrantes, uma vez que seus direitos elementares são negados em uma sociedade marcada pela desigualdade. Segundo Sposati (2011, p. 8), “quanto mais frágeis forem às condições da família, mais será necessário acionar mecanismos protetivos".

Ao refletir sobre quem são essas famílias presentes no Programa, verifica-se que todos os beneficiários eram mulheres. Para fazer frente à condição da mulher nos dias atuais, várias políticas públicas, embora não diretamente voltadas à população feminina, contribuem para a ampliação da sua autonomia pessoal e autossustentação (GODINHO, 2004).

Em contrapartida, de acordo com Passos (2017, p. 90),

[...] é sabido que a discriminação em relação às mulheres muitas vezes se esconde sob a forma de proteção à fragilidade feminina, que encobre a cultura patriarcal de opressão e submissão. Nessa realidade de opressão mascarada, a intervenção do Estado, através de políticas públicas para as mulheres, é fundamental para superar as assimetrias de gênero.

Nesse sentido existem duas posturas que podem ser adotadas quando se trata da execução de políticas para as mulheres: uma que enfatiza o papel que a mulher desempenha na família; e outra que enfatiza os direitos da mulher enquanto sujeito social, sendo um movimento no sentido da extensão da cidadania. Dessa forma têm sido realizados programas que reforçam a primeira postura, com pouca ligação com a segunda (PASSOS, 2017, p. 90).

Segundo Mészáros (apud CISNE, 2014, p. 18):

[...] as mulheres compõem $70 \%$ dos pobres do mundo e, além de serem 
responsabilizadas pela reprodução social, são também as maiores vítimas da precarização das políticas públicas, por encontrarem-se inseridas na informalidade e em empregos, sem garantias ou direitos trabalhistas assegurados. São elas, portanto, que estão no cotidiano da Assistência Social buscando a garantia mínima das condições de sobrevivência de suas famílias.

Apesar do PBF não ser uma política dirigida exclusivamente a mulheres, e sim à família, observa-se predominância destas em todo o território nacional, corroborando os achados da presente investigação. A Secretaria Especial de Política para Mulheres, ligada ao Ministério da Cidadania e Justiça de Brasília, aponta que mais de 90\% dos beneficiários são mulheres, implicando em maior controle sobre as contas da casa, e algumas vezes essa autonomia pode ir além das questões financeiras (BRASIL, 2012).

Segundo Moreira et al., (2012), a entrada das mulheres no PBF contribuiu positivamente para a promoção de sua autonomia, emancipação e autoestima, afirmando que o benefício trouxe efeitos no reordenamento no ambiente doméstico e o acesso feminino ao espaço público (como participação em conselhos comunitários e escolares), de forma a possibilitar às mulheres maior poder de troca, maior capacidade de fazer escolhas e maior poder de decisão sobre o uso do dinheiro, conforme relato abaixo:

Eu acho que o Bolsa família ajuda muito as pessoas. Tem momento que você vai fazer sua comida, tua janta, você não tem o que pôr na mesa, e chega naquele dia, você tem o dinheirinho do Bolsa Família pra contar. Ajuda muita gente. É o dia que tem o dinheiro que eu sei que tá lá, tal dia vai estar lá na minha conta. Me ajuda bastante $(\mathrm{P}-11)$.

Considerando-se o significado do dinheiro e suas diversas funções, a literatura analisa que ele acarreta certa libertação e uma maior responsabilização. "A cada acréscimo de liberdade, aumenta a responsabilidade" (PINZANI; REGO, 2014, p. 212). Para Carlotto e Mariano (2012, p. 267), “o fato de o PBF privilegiar a titularidade feminina e condicionar o recebimento do benefício à presença das crianças na escola, além da atenção básica à saúde, aumenta a responsabilidade das mulheres para com os filhos".

Como as mulheres são as principais destinatárias do benefício em nome da família, torna-se importante analisar, a partir dos achados, as relações de gênero presentes no PBF. Cabe salientar que tais mulheres, principalmente a partir do recebimento do benefício em seu próprio nome, passaram a ter mais poder de decisão na vida em família, fazendo com que se sintam mais valorizadas, porém, lado outro, tornam-se mais responsáveis pelo cumprimento das condicionalidades do Programa. 
Culturalmente, toda responsabilidade e cuidado com os filhos incidem sobre as mulheres, desde acompanhar o crescimento e desenvolvimento, a vida escolar, manter a vacinação em dia e participar das ações na área de Assistência Social. Cabe ainda a responsabilidade de atualização do cadastro para a permanência no programa, uma vez que o cartão está em seu nome (NASCIMENTO, 2015).

Traz para a reflexão que a política pública, a exemplo do PBF, atua no sentido de olhar para os responsáveis familiares, em sua maioria mulheres, cujas ações dos profissionais algumas vezes subtraem a responsabilidade dos homens, enfatizando a profunda desigualdade de gênero.

\section{O olhar do beneficiário frente às mudanças decorrentes do Programa}

Ao levar o beneficiário a refletir sobre as principais mudanças ocorridas em suas vidas após o ingresso no programa, estes afirmam que, apesar de pouco, o valor recebido ajuda sobremaneira, principalmente porque permite comprar o que está faltando, o que os filhos estão precisando, comprar alimentos de que os filhos gostam; entendem que antes do PBF isso não era possível.

Percebe-se que os beneficiários compreendem o PBF como um complemento da renda familiar, justamente para auxiliar no provimento do sustento da família. Outro autor Rosinke et al. (2011) constatou também que os recursos do PBF destinados às famílias de baixa renda, contribuem para o desenvolvimento da economia local e também para o bem-estar das mesmas. Salientou que o Programa melhora, mesmo que minimamente, a renda das famílias assistidas, complementando o orçamento familiar e contribuindo para o aumento em sua qualidade de vida.

Uma das participantes afirma:

Depois que eu comecei a receber, melhorou um pouco, às vezes elas (as crianças) queriam uma coisa e não tinha dinheiro, ai comecei a receber, consigo comprar bolacha, leite, essas coisas para as meninas comerem (P-14).

Observou-se que foi recorrente o entendimento dos beneficiários de que as mudanças ocorridas em suas vidas estão ligadas especialmente ao fato de poder adquirir alimentos. Assim, a alimentação novamente aparece como primordial. $O$ fato de a transferência monetária estar na titularidade da mulher, em alguns casos, a torna capaz de fazer um planejamento financeiro para ampliar suas perspectivas e oportunidades, pois 
ninguém melhor que a própria família para definir o melhor uso do dinheiro (CAMPELLO, 2013

p. 17). Alguns participantes definem tal perspectiva:

Bolsa Família me ajudou muito, muita coisa mudou depois que comecei a receber. Na parte de educação pude comprar mais materiais de escola, alimentação, parte da estrutura da casa consegui arrumar, aumentei um quartinho para os meus meninos que antes dormia comigo (P-9).

É aquilo né, o Bolsa Família, hoje pra mim, eu não me vejo sem ele, porque é essencial, é o pouco que pra mim é muito (P11).

Voltei até a estudar, estou desempregada mais estou estudando. Porque ajuda, não preciso me preocupar. Eu tinha parado na 8$^{\underline{a}}$ série, conclui o 8 $^{\underline{a}}$ aí fui para o $1^{\underline{a}}$, fui firme aí me mandaram embora de onde eu trabalhava, aí fiquei desanimada mais eu não podia parar, aí comecei a fazer faxina, ai eu saio da faxina e vou direto pra escola, as vezes não dá nem tempo de passar em casa. Eu quero terminar, quero um serviço melhor para mim, porque eu sei que eu sou a estrutura pra eles, estão todos crescendo e eu sou modelo pra eles, sou a base. Que nem eu falo para eles se eu não estiver aqui como vai ser? (P-1).

Nos relatos das entrevistadas foi possível perceber que cada uma delas, em sua subjetividade, concebe o PBF de diferentes formas. A entrevistada P-11 deixa claro que o valor recebido está incorporado na vida desta beneficiaria, considerando-se que a mesma o recebe há 15 anos, não visualizando sua vida sem o mesmo. Pondera-se sobre a situação de dependência gerada pelo programa, uma vez que não está considerando a temporalidade do benefício, sua fiscalização bem como a ausência de um sistema de articulação entre as políticas que contemple a integralidade do atendimento. Cabe ressaltar que a referida beneficiária já recebia outros benefícios sociais que foram agrupados com a denominação de $\mathrm{PBF}$, perfazendo os 15 anos referidos.

Já no relato da entrevistada P-1, observa-se o quão importante tem sido o benefício, para seu desenvolvimento pessoal. Apesar do pouco tempo de recebimento ( 2 anos), isso leva a questionar sobre que fatores determinam os diferentes caminhos assumidos por cada beneficiário. No relato citado fica claro que a beneficiária valoriza o estudo para a melhoria em sua condição social e a busca de melhor oportunidade de trabalho.

Alvarenga assim preleciona que foi importante notar nuanças em relação ao papel da escola como forma de enfrentamento da pobreza, destacando:

A importância do Programa Bolsa Família (PBF) ao longo desta última década. O objetivo central do programa é o incentivo à garantia de direitos e não apenas proporcionar renda às famílias que se encontram em circunstâncias de pobreza e extrema pobreza. Associam-se, portanto, transferência de renda e acesso aos direitos sociais básicos de saúde, alimentação, educação e assistência social 
(CRAVEIRO; XIMENES, 2013, p. 109).

Considerando que um dos objetivos do PBF é contribuir para o rompimento da transmissão intergeracional da pobreza no Brasil, é preciso reconhecer que a educação constitui-se também em uma relevante estratégia para alcançar tal objetivo. Os estudos realizados sobre o acesso e a permanência dos estudantes na escola vêm demonstrando que a desigualdade social e econômica tem dificultado a universalização da educação básica.

Para o especialista em educação Carlos Roberto Jamil Cury (2002, p. 179),

Essa desigualdade, hoje medida por vários instrumentos de análise (como o índice de desenvolvimento humano IDH), faz com que haja problemas na escola - que não são da escola. Por isso, não é desprezível o impacto desta situação fática sobre o conjunto do sistema educacional em matéria de acesso, permanência e sucesso. É de se perguntar se é possível desconsiderar a desigualdade socioeconômica como uma geradora remota das dificuldades próximas que afetam o desempenho intraescolar dos alunos.

Importante considerar os elementos que constituem o PBF: contribuir para a superação e a quebra da transmissão intergeracional da pobreza no Brasil; proteger a família inteira em vez do indivíduo; potencializar as ações de governo, articulando União, estados e municípios; construir uma gestão configurada em redes; e assumir a educação como direito coletivo, subjetivo inalienável. Este conjunto de elementos exige que as práticas e os processos pedagógicos adotados sejam repensados em sua multidimensionalidade. Assim, a educação, entendida como um direito individual humano e coletivo, com poder de habilitar para o exercício de outros direitos e potencializar o ser humano como cidadão pleno, criam condições para tornar os cidadãos de diferentes condições sociais, étnicas e intelectuais aptos para viverem, conviverem em determinado ambiente, em sua dimensão planetária. A educação, assim entendida, inscreve-se no processo e na prática que se concretizam nas relações sociais. Como tal, transcende o espaço e o tempo escolares, tendo em vista os diferentes sujeitos que a demandam (CRAVEIRO; XIMENES, 2013).

De acordo com Paulo Freire (1981, p. 15-16), "para a concepção crítica, o analfabetismo nem é uma 'chaga', nem uma 'erva daninha' a ser erradicada (...), mas uma das expressões concretas de uma realidade social injusta". É sobre esta realidade injusta que a conquista ao direito à educação torna-se, cada vez mais, uma exigência a ser observada, para que se possa preparar sujeitos escolares capazes de transitarem no mundo social em geral e, em particular, no mundo do trabalho. 
O pagamento do benefício por meio de cartão pessoal e a priorização dada à mulher como titular deste cartão - hoje, $93 \%$ dos titulares são mulheres - proporcionaram o empoderamento feminino em espaços públicos e privados. O ganho de autonomia das mulheres e de ampliação da cidadania, é um dos principais indicadores do potencial intrínseco de mudança na sociedade, dependente apenas do impulso proporcionado por políticas adequadas (PINZANI; REGO, 2014).

Ainda refletindo sobre as mudanças ocorridas, alguns entrevistados também se posicionaram com críticas relacionadas ao funcionamento e fiscalização. Vale ressaltar que essa fiscalização deve se dar através de uma gestão descentralizada e compartilhada entre União, estados, Distrito Federal e municípios, em ações conjuntas para aperfeiçoar, ampliar e, portanto, fiscalizar a execução do mesmo (SANTOS et al., 2014), conforme Resolução no 15, do Conselho Nacional de Assistência Social (CNAS) de junho de 2014, que orienta os Conselhos de Assistência Social quanto à organização e funcionamento na participação e no controle social do Programa Bolsa Família-PBF (ROSINKE et al., 2011, p. 82). Segundo a pesquisa, a participante relata:

Eu acho que o Bolsa família, tinha que ter uma fiscalização, porque tem muita coisa errada. Eu mesmo sei de família que tem casa própria, tem carro, tem uma vida de luxo e recebe o Bolsa família. Eu acho que tinha que buscar ir atrás do endereço, visitar a família, está ali pra descobri essas coisas erradas que tem muito. Pra eles ver, pra onde está indo mesmo, se está indo pra família que precisa ou não (P-12).

Apesar do reconhecimento da importância do benefício, os entrevistados identificaram a falta de condições de promoção de acesso ao trabalho, pois relataram o significado de ter um trabalho fixo com salário digno, ficando evidente aqui uma das contradições do programa, que o mesmo não estimulou, deixando clara a preocupação de não se conseguir um trabalho formal devido à baixa escolaridade que possuem.

O Bolsa Família não permitiu acesso ao trabalho, porque não tem trabalho, não tem oportunidade pra nós, se eu for em um escritório ninguém vai querer desse jeito, se for atendente, então não permite acesso ao trabalho, porque 112,00 reais, você não paga um curso, por isso que eu falo tem que dar um curso profissionalizante, não curso básico, pra você falar assim eu tenho capacidade, tinha que dar diploma, e uma chance da gente trabalhar, abrir uma firma para as mulheres, não precisa ser uma firma grande, nem que fosse reciclagem, tem estado que tem reciclagem pras mulheres que recebe o bolsa família, aqui não tem. Estado menor que esse, mais pobre e tem reciclagem, tem catadoras de lixo, ganhando um dinheirinho básico, só aqui que não tem (P-8). 
Importante considerar que toda política pública traz uma ação reflexiva, despertando sentimentos e comportamentos nos indivíduos, direta ou indiretamente, podendo gerar conflitos de opiniões e interesses daqueles que dela se beneficiam (ROMÃO; ORSI; TERENCE, 2014).

Pensar em direitos, especialmente nas políticas compensatórias como o PBF, remete à reflexão sobre as políticas, programas, práticas, intervenções e ações que possibilitem a todo ser humano as condições necessárias para viver com o mínimo de dignidade, o que significa negar qualquer ação que se restrinja meramente à sobrevivência. Assim entendeu outra participante:

Melhorou bastante a educação. Porque na escola eles utilizam muita coisa da internet, com o dinheiro do bolsa família eles vão na lan house, consegui agora também um computador pra eles estudarem em casa (P-9).

Para uma educação de qualidade no compromisso da produção e reprodução de conhecimento, a assiduidade nas atividades escolares é condição fundamental. Tal vai ao encontro das pesquisas, que apontam a condicionalidade da educação com resultados positivos.

Segundo o Ministério do Desenvolvimento Social e Combate à Fome, o índice de acompanhamento da frequência escolar dos alunos beneficiários do Bolsa Família subiu de $85,57 \%$ para $91,8 \%$ em agosto e setembro de 2016 , comparado ao bimestre anterior. Desta forma, 95,2\% dos quase 13,9 milhões de crianças e jovens entre 6 e 17 anos que são acompanhados atingiram a frequência escolar exigida para a transferência de renda (BRASIL, 2008). Na região estudada, em 2016, na área da educação, entre o público de 6 a 17 anos, a porcentagem acompanhamento escolar nos mês março foi 91\%, julho 92,19\%, e de setembro foi de $95,80 \%$. Em 2017, em março, foi $93,88 \%$; julho, $93,17 \%$, e setembro, $95,87 \%$. Em março de 2018 foi de 94,89\%; julho, 96,24 e setembro, 97\% (BRASIL, 2019).

A educação melhorou, melhorou sim. Melhorou porque meus filhos faltavam na aula, agora eles estão faltando menos, entendeu? Então quando eu comecei a receber, ai eles pararam de faltar muito na aula, melhorou um pouco né (P-15).

Na saúde melhorou, porque tem que ter o cadastro todo mês lá, para a pesagem, para avaliar a criança. Elas vão lá perguntam se as crianças estão bem (P-1).

Na saúde eu passo pelo médico do SUS, então eu tenho tudo de graça, remédio de graça eu vou ganhar o aparelho auditivo de graça. Melhorou muito o atendimento $(\mathrm{P}-13)$. 
Observa que os beneficiários do Programa Bolsa Família, apesar de terem a percepção de que sua vida tenha melhorado com as condicionalidades, ainda não tem condições de reconhecer que outra política possa ter efeito em suas condições de vida como por exemplo, a Política de Habitação. Todavia alguns entrevistados mencionam a possibilidade do Programa oferecer acesso ao emprego e renda, através de uma política que as qualificasse para se tornarem competitivas ao mercado de trabalho.

\section{Desafios e possibilidades do Programa Bolsa Família}

Sabe-se que o Programa Bolsa Família constitui importante mecanismo para a promoção de cidadania e inclusão através das políticas sociais, especialmente saúde, educação e assistência social. A concessão dos benefícios tem caráter temporário e não geram direito adquirido, sendo obrigatória a revisão da elegibilidade das famílias a cada 2 anos. $\mathrm{Na}$ amostra estudada foi encontrado pessoas que recebiam o benefício há mais de 10 anos devido a serem oriundas de programas anteriores ao Bolsa Família, que não contemplavam as condicionalidades. Todavia, após o Bolsa Família, essas pessoas tiveram que se adequar. Diante da temporalidade do benefício, os entrevistados disseram o que pensam dessa situação:

Olha (o benefício) vai fazer falta, mas a gente tem que pensar nisso sim. Eu faço faxina né, e eu estou procurando serviço para ver se consigo registrar, e quando eu registrar eu venho aqui e cancelo (P-1).

Não estou preparada para deixar de receber. A gente tem que pensar em se organizar né, por que vai fazer o que, o que a gente vai poder fazer? Eu acho que vai ter famílias que vai passar muita dificuldade por causa disso (P-5).

A gente sabe que uma hora ou outra, vai ser cortado que não vai ter mais, mas a gente vai é sentir muita falta, porque não tem né. Ah nem sei o que eu vou fazer se perder. Imagina, porque muitos aí falam que vai ser cortado o Bolsa família, porque a Dilma vai sair, não sei como, mas falam. Mas imagina se um dia acontecer isso, nossa senhora, muita gente vai ficar difícil meu pai do céu (P-12).

Nesses relatos, as beneficiárias demonstraram ter consciência da temporalidade do programa; contudo, apesar de inseridas em um programa que visa à emancipação das famílias, poucos tiveram incentivos de buscar políticas de educação e/ou mercado de trabalho.

Segundo Bueno (2017), o trabalho faz parte das necessidades humanas e surge com 
o próprio homem, que precisa trabalhar para sobreviver. O trabalho não é a satisfação de uma necessidade, mas apenas um meio para satisfazer outras necessidades e condição necessária para ser cada vez mais livre e dono de si próprio. Alguns relatos refletem o sentido que tem o trabalho para o homem (BUENO, 2017).

\begin{abstract}
Eu passo apuro, eu corro para onde? Aqui para Assistente Social do CRAS. Não tem as coisas lá em casa, fico até com vergonha, ela faz um papel e eu busco cesta. Eu preferia não receber a Bolsa Família e ter um emprego, eu, se eu ganhasse um salário, ia fazer muito mais efeito do que $R \$ 112,00$ reais, não precisaria nem ser $o$ salário mínimo, se eu tivesse um salário fixo de $R \$ 600,00$, para mim já estava ótimo, já ajudava bem minha casa, porque eu passo apertado (P-8).

Trabalho tá difícil, o BF não permitiu acesso ao trabalho não. Na hora que tiver que trabalhar vou trabalhar não é por causa do bolsa família que vai deixar de trabalhar né. Porque as meninas sempre trabalharam (P-14).
\end{abstract}

Muitas beneficiárias relataram estar preparadas para deixar de receber o PBF desde que tenham a garantia de um emprego, de políticas públicas efetivas e de condições dignas de manutenção familiar.

Para que a situação de dependência do programa não se instale, é necessário pensar estratégias, políticas públicas com mais possibilidades de promoção da cidadania, oportunidades de uma vida mais digna com acesso aos direitos sociais básicos, através de diagnósticos coesos, planejamento, adoção de projetos, programas e ações, em parceria ou não com outras políticas públicas. O município deve articular com os programas existentes nas demais esferas de governo e na sociedade civil para ofertá-los a seus beneficiários. Mas, para que essas ações sejam mais efetivas, é imperioso identificar programas que considerem a realidade e necessidade local e as especificidades dos beneficiários.

Segundo Silva, Yazbek e Di Giovanni (2004), essa intencionalidade, para que seja materializada, requer que se priorizem e democratizem os programas e serviços sociais básicos, o que significa alterar o quadro conjuntural contemporâneo, dando lugar para uma política de crescimento econômico, de geração de emprego e de distribuição de renda que seja articulada à política social (SILVA; YAZBEK; DI GIOVANNI, 2004).

Assim, pensar na inclusão socioprodutiva dos beneficiários do PBF é uma estratégia de médio e/ou longo prazos, que leve em consideração um conjunto articulado de ações das três esferas de governo e dos setores não governamentais. Os gestores devem buscar parceiros internos e externos que possam contribuir com esse processo, pensando em estratégias de promoção à cidadania, ações como parcerias e trabalhos articulados com 
órgãos municipais de educação, qualificação profissional e de emprego e renda, sindicatos de trabalhadores urbanos, Sebrae, Senai, Senac, investimento em educação de jovens e adultos, apoio ao associativismo e à comercialização, criação de mais creches, ações com empresários e cooperativas de crédito entre outras (CRUZ, 2007).

Preparada a gente nunca está, mais a gente encara. Eu estou a procura de serviço. Então penso em me organizar a partir do momento que eu encontrar um emprego que dê para eu alimentar meus filhos (P-4).

Ah! tem que tá prepara, vai ser difícil, porque com o aumento do desemprego, o emprego não está fácil. Vai ficar difícil depois, se eu parar de receber, é que às vezes eu conto só com esse dinheiro pra comprar alguma coisa. Às vezes a gente tem que estar preparada, mas se corta a gente vai fazer o que (P-14).

Ah! com certeza estou preparada pra deixar de receber o BF. Tipo assim eu faço bico, eu trabalho, a gente vai, eu faço bico, não fico parada, eu sempre faço alguma coisa. Eu só não trabalho pra fora, por causa do meu filho, não tem como deixar ele em casa sozinho (P-10).

Estou, tentando ainda ficar preparada pra deixar o $B F$, o desemprego está bravo. Não acha emprego, nem na roça, não tem nada, não chega a 40,00 reais a diária, no sol o dia inteiro, meu Deus! Eu não consigo arrumar nada, mas eu estou entregando currículo, não é possível que esse ano 2016 não vai chamar, misericórdia! (P-8).

Nos relatos dos participantes dessa investigação, ficou evidente a dificuldade de acesso ao trabalho formal. Todavia, alguns exercem funções informais, sendo o BF considerado um complemento de renda. Conforme Sen discorre, oferecer às mulheres educação e emprego, além de fortalecer sua autonomia, pode ser o primeiro passo para aumentar seu poder e voz dentro e fora da família e permitir sua inclusão em um contexto social que antes as excluía (SEN, 2010). Um dos maiores desafios do programa é articular políticas de educação e emprego que possam mudar a vida das pessoas. Sem ações intersetoriais com outras políticas que permitam educação e acesso ao emprego, torna-se difícil o empoderamento que fortaleça as famílias na superação de suas necessidades.

Cabe ressaltar o papel da sociedade civil na gestão do PBF como contribuição para uma maior transparência das ações do Estado e garantia de acesso das famílias mais vulneráveis ao Programa. Essa participação dá-se por meio da comissão de Controle Social, exercido junto aos conselhos municipais de assistência social, cujos objetivos são acompanhar e estimular a integração e a oferta de outras políticas públicas que favoreçam a emancipação das famílias beneficiárias do PBF (BRASIL, 2010).

É importante divulgar à comunidade local os programas complementares ao PBF que deveriam ser desenvolvidos no município. Também se faz relevante identificar as 
potencialidades para a criação e implementação de programas próprios, observando-se as características do município e as necessidades da população em situação de maior vulnerabilidade (BRASIL, 2010).

\section{Considerações finais}

Programas de transferência de renda têm se tornado divisor de águas entre os que estudam as políticas sociais. Além de alterar o mapa da pobreza no país e oferecer um mínimo de dignidade a pessoas subalternizadas, o PBF, ao mesmo tempo, tem proporcionado reflexões sobre as políticas públicas. Ficou evidente e recorrente no estudo que a mudança ocorrida na vida dos beneficiários após o recebimento do benefício foi o acesso à alimentação diversificada, de qualidade e o quanto isso foi importante na vida da família. Portanto, o PBF proporcionou acesso a direitos básicos, como a alimentação.

Foi identificada também a ausência de esforços articulados intersetoriais para reduzir os diversos aspectos da pobreza, como a falta de emprego, déficits habitacionais, serviços públicos precários, ausência de renda, entre outros. No conjunto, as políticas sociais perdem musculatura ao ignorar as possibilidades de trabalhar de forma articulada, num sistema bem estruturado de qualidade, inclusive no âmbito municipal, uma vez que práticas segmentadas entre as políticas é algo recorrente. É possível afirmar que a população em questão, de certa forma, permanece invisível aos olhos das instituições e políticas públicas vigentes, principalmente, quando relata que os familiares não foram incentivados a buscar os estudos tampouco o acesso a formas de ingresso ao mercado de trabalho.

Não bastam ações pontuais para resolver o problema da pobreza; é necessário que se garanta o acesso a serviços públicos de qualidade, isto é, articular programas de transferência de renda com serviços e programas sociais básicos para democratizar o acesso a quem deles necessite.

Vale ressaltar que o PBF trouxe mudanças na participação dessas famílias no processo educacional de seus filhos e maior acesso ao cuidado em saúde. As condicionalidades também proporcionaram importante acesso para os beneficiários porque se pode perceber que eles tiveram garantia de entrada nas Política de Educação e Saúde. E por efeito também essas políticas se valorizam tento como uma das principais sustentação e condições do programa a prática de utiliza-las, e usufruir de seus direitos enquanto uma política pública.

Para dar conta das diversas vulnerabilidades dessas famílias, o país necessita 
fomentar um banco de dados amplo e eficiente, objetivando o planejamento de políticas públicas articuladas intersetorialmente, para que a longo prazo a articulação de ações entre as várias políticas possa ter reflexos na sociedade. O processo de erradicação ou combate à pobreza é meta e exigência do conjunto de políticas econômicas e sociais e não de uma só política.

Ficou evidente a dificuldade em acessar outras políticas como as que visam à garantia de emprego e renda.

Embora não seja objetivo do programa o enfrentamento das desigualdades de gênero, observa-se que essa e outras vulnerabilidades marcam a vida dessas mulheres, pois elas são responsáveis por receber o benefício e fazer cumprir as condicionalidades. Esse fato reforça a desigualdade de gênero, o que não significa que o PBF não tenha possibilitado avanços na inclusão social e econômica dessas mulheres. Uma das mudanças ocorridas foi a autonomia das mulheres diante do poder de compra, em que pesem serem visíveis as privações e o peso da responsabilidade por elas vividas.

Os relatos apontaram a importância do PBF em suas vidas, principalmente por ter seu foco no combate à fome e à pobreza. No olhar das beneficiarias entrevistadas, o maior ganho do PBF foi o alívio à pobreza imediata.

Apesar da vasta literatura sobre o PBF, cabe o questionamento sobre o fato de este não ter implementado mudanças estruturais no sistema de proteção social que pudessem resistir às possíveis alterações partidárias na gestão das políticas públicas. Importante refletir o Programa Bolsa Família enquanto Política de Estado e não de Governo.

As desigualdades social e econômica vivenciadas por essas famílias revelam que o desenvolvimento social só será alcançado quando todas as barreiras forem superadas por meio de ações públicas que as fortaleçam e garantam a sua dignidade.

\section{Referências}

ÁLVARES, Luciana Castro; JOSÉ FILHO, Mário. O serviço social e o trabalho com famílias. Revista Serviço Social \& Realidade, Franca, SP, v. 17, n. 2, p. 9-26, 2008.

ÁVILA, Milene Peixoto. Que pensam as beneficiárias do Bolsa Família? Revista de Ciências Sociais, Porto Alegre, n. 38, p. 105-22, 2013.

BARDIN, Laurence. Análise de conteúdo. Lisboa, Portugal: Edições 70, 2010. 
BRASIL. Decreto no 6.392, de 12 de março de 2008. Altera o Decreto no 5.209, de 17 de setembro de 2004, que regulamenta a Lei no 10.836, de 9 de janeiro de 2004 - Programa Bolsa Família. Brasília, DF: Presidência da República, 2008.

BRASIL. Ministério do Desenvolvimento Social e Combate à Fome. Guia de atuação das instâncias de controle social do Programa Bolsa Família. 2. ed. Brasília, DF: Ministério do Desenvolvimento Social e Combate à Fome, 2010.

BRASIL. Ministério da Mulher, da Família e dos Direitos Humanos. Mulheres correspondem a 93\% dos titulares do Bolsa Família. Brasília, DF: Secretaria de Justiça e Cidadania, 2012. Disponível em: http://www.brasil.gov.br/cidadania-ejustica/2012/01/ mulherescorrespondem-a-93-dos-titulares-do-bolsa-familia. Acesso em: 25 mar. 2017.

BRASIL, Ministério da Cidadania - Secretaria Nacional de Renda e Cidadania - Bolsa Família e Cadastro Único no seu Município, 2019. Disponível em: https://aplicacoes.mds.gov.br/sagirmps/bolsafamilia/painel.html. Acesso em 30 dez. 2019.

BRASIL. Ministério do Desenvolvimento Social e Combate à Fome. Secretaria Nacional de Renda e Cidadania - Senarc. Bolsa Família Transferência de renda e apoio à família no acesso à Saúde, à Educação e à Assistência Social, 2012. Disponível em: https://www.mds.gov.br/webarquivos/publicacao/bolsa familia/Cartilhas/Cartilha_BolsaFa milia.pdf. Acesso em 25 mar. 2017.

Brasil. Ministério do Desenvolvimento Social e Combate a Fome. Conheça o Programa Bolsa Família, 2015. Disponível em: http://www.mds.gov.br/assuntos/bolsa-familia/o-que-e. Acesso em 25 mar.2017.

BUENO, Clodoaldo. O Trabalho e o homem: o ser humano é o único que consegue transformar a natureza através de seu trabalho. Revista Pré Univesp., São Paulo, SP, n. 61, 2017. Disponível em: http:// pre.univesp.br/o-trabalho-e-o-homem\#.WSWleOvyuUk. Acesso em: 20 abr. 2017.

BUENO, Marina. As condicionalidades do Programa Bolsa Família: o avesso da cidadania. Lugar Comum, Rio de Janeiro, n. 29, p. 33-46, 2009. Disponível em: https://docplayer.com.br/7858607-As-condicionalidades-do-programa-bolsa-familia-oavesso-da-cidadania.html. Acesso em: 20 abr. 2017.

CAMPELLO, Tereza. Uma década derrubando mitos e superando expectativas. In: CAMPELLO, Tereza; NERI, Marcelo Côrtes Neri (ed.). Programa Bolsa Família: uma década de inclusão e cidadania. Brasília: IPEA, 2013. p. 15-24.

CARLOTO, Cássia Maria; MARIANO, Silvana Aparecida. Empoderamento, trabalho e cuidados: mulheres no programa bolsa família. Textos \& Contextos, Porto Alegre, v. 11, n. 2, p. 258-272, 2012.

CISNE, Mirla. Feminismo e consciência de classe no Brasil. São Paulo: Cortez, 2014.

CRAVEIRO, Clélia Brandão Alvarenga; XIMENES, Daniel de Aquino. Dez anos do Programa Bolsa Família: desafios e perspectivas para a universalização da educação básica no Brasil. In: 
CAMPELLO, Tereza; NERI, Marcelo Côrtes Neri (ed.). Programa Bolsa Família: uma década de inclusão e cidadania. Brasília: IPEA, 2013. p. 109-124.

CRUZ, Maria do Carmo Meirelles Toledo. Observatório do Programa Bolsa Família do Estado de São Paulo: Situação de Gestão. In: CONGRESSO CONSAD DE GESTÃO PÚBLICA, 2., 2007, Brasília, DF. Livro de resumos [...]. Brasília: CONSAD, 2007. p. 1-34. Tema: Painel 19: implementação de Processo de Monitoramento e Avaliação dos Programas de transferência de Renda.

CURY, Carlos Roberto Jamil. A educação básica no Brasil. Educação e Sociedade, Campinas, SP, v. 23, n. 80, p. 168-200, 2002. Disponível em:

https://www.scielo.br/pdf/es/v23n80/12929.pdf. Acesso em: 20 abr. 2017.

FONTANELLA, Bruno José Barcellos; RICAS, Janete; TURATO, Egberto Ribeiro. Amostragem por saturação em pesquisas qualitativas em saúde: contribuições teóricas. Cadernos de Saúde Pública, Rio de Janeiro, RJ, v. 24, n. 1, p. 17-27, jan. 2008.

FREIRE, Paulo. Ação cultural para a liberdade. 5. ed. Rio de Janeiro: Paz e Terra, 1981.

GIL, Antônio Carlos. Métodos e técnicas de pesquisa social. 6. ed. São Paulo: Atlas, 2010.

GODINHO, Tatau. Construir a igualdade combatendo a discriminação. In: GODINHO, Tatau; SILVEIRA, Maria Lúcia (ed.). Políticas públicas e igualdade de gênero. São Paulo:

Coordenadoria Especial da Mulher, 2004. p. 55-64.

LIMA, Luciana. Porta de saída do Bolsa Família existe, mas ainda é estreita. Último Segundo: IG, São Paulo, SP, 20 out. 2013. Bolsa Família. Disponível em:

https://ultimosegundo.ig.com.br/bolsa-familia/2013-10-20/porta-de-saida-do-bolsa-familiaexiste-mas-ainda-e-estreita.html. Acesso em: 20 abr. 2017.

MAGALHÃES JÚNIOR, Helvécio Miranda; JAIME, Patrícia Constante; LIMA, Ana Maria Cavalcante de. O papel do setor saúde no Programa Bolsa Família: histórico, resultados e desafios para o Sistema Único de Saúde. In: CAMPELLO, Tereza; NERI, Marcelo Côrtes Neri (ed.). Programa Bolsa Família: uma década de inclusão e cidadania. Brasília: IPEA, 2013. p. 93-108.

MINAYO, Maria Cecília S. O desafio do conhecimento: pesquisa qualitativa em saúde. 9. ed. São Paulo: Hucitec, 2006.

MOREIRA, Nathalia Carvalho; FERREIRA, Marco Aurélio Marques; CARVALHO LIMA, Afonso Augusto Teixeira de Freitas; CKAGNAZAROFF, Ivan Beck. Empoderamento das mulheres beneficiárias do Programa Bolsa Família na percepção dos agentes dos Centros de Referência de Assistência Social. Revista de Administração Pública, Rio de Janeiro, RJ, v. 46, n. 2, p. 403-423, mar. /abr. 2012.

NASCIMENTO, Maria Antônia Cardoso. Tempo de bolsas: estudos sobre programas de transferência de renda. Campinas: Papel Social, 2015.

NERI, Marcelo Côrtes. Sistemas de pagamento subnacionais baseados no Bolsa Família. In: CAMPELLO, Tereza; NERI, Marcelo Côrtes Neri (ed.). Programa Bolsa Família: uma década de inclusão e cidadania. Brasília: IPEA, 2013. p. 125-136. 
PASSOS, Luana. Gênero: dimensão contemplada no Bolsa Família? Textos \& Contextos, Porto Alegre, v. 16, n. 1, p. 83-99, jan. /jul. 2017.

PINZANI, Alessandro; REGO, Walquiria Domingues Leão. Vozes do Bolsa Família: autonomia, dinheiro e cidadania. 2. ed. São Paulo: Unesp, 2014.

ROCHA, Sharlene França; SOARES, Jaqueline Lima; ALCÂNTARA REIS, José Guilherme; CARDOSO, Jonas. Análise da qualidade de vida dos beneficiários do Programa Bolsa Família na cidade de Porto Velho. Revista Pesquisa \& Criação, Porto Velho, RO, v. 10, n. 2 p. 59-73, 2011.

ROMÃO, Wagner de Melo; ORSI, Rafael Alves; TERENCE, Ana Cláudia Fernandes. Estudos em políticas pública: cidadania, desenvolvimento e Controle Social. São Paulo: Cultura Acadêmica, 2014.

ROSINKE, João Germano; HECK Cláudia Regina; DALFOVO, Wylmor Constantino Tives; RUSCHEINSKY, Aloisio. Efeitos sociais e econômicos para o desenvolvimento local através das contribuições do Programa Bolsa Família no município de Sinop-MT no período de 2004 a 2009. Interações, Campo Grande, v. 12, p. 77-88, jan./jun. 2011.

SANTOS, Cláudia Roberta Bocca; MAGALHÃES, Rosana. Pobreza e Política Social: a implementação de programas complementares do Programa Bolsa Família. Ciência e Saúde Coletiva, Rio de Janeiro, RJ, v. 17, p. 1215-1224, 2012.

SANTOS, Michelle Costa Marques dos; GOUVEIA JUNIOR, Antônio; OLIVEIRA, Paulo Roberto Marques de; MELO, Daniel Reis Armond de; SOUZA, Waldemar Antônio da Rocha de. A voz do beneficiário: uma análise da eficácia do Programa Bolsa Família. Revista de Administração Pública, Rio de Janeiro, RJ, v. 48, p. 1381-1405, nov. /dez. 2014.

SEN, Amartya. Desenvolvimento como liberdade. São Paulo: Companhia das Letras, 2010.

SENNA, Mônica de Castro Maia; BURLANDY, Luciene; MONNERAT, Giselle Lavinas; SCHOTTZ, Vanessa; MAGALHÃES, Rosana. Programa Bolsa Família: nova institucionalidade no campo da política social brasileira? Revista Katálysis, Florianópolis, SC, v. 10, n. 1, p. 86-94, jan./jun. 2007.

SILVA, Maria Ozanira da Silva e. O Bolsa Família: verso reverso. Campinas: Papel Social, 2016.

SILVA, Maria Ozanira da Silva e; LIMA, Valeria Ferreira Santos de Almada Lima. Avaliando o bolsa família: unificação, focalização e impactos. 2. ed. São Paulo: Cortez, 2014.

SILVA, Maria Ozanira da Silva e; YAZBEK, Maria Carmelita; DI GIOVANNI, Geraldo. A política social brasileira no século XXI: a prevalência dos programas de transferência de renda. São Paulo: Cortez, 2004.

SOUSA, Darcon; BRITO, Alisson Felipe de Melo. Os mecanismos de "portas de saída" do programa bolsa família e as perspectivas dos beneficiários no município de caturité, Paraíba. In: JORNADA INTERNACIONAL DE POLÍTICAS PÚBLICAS, 7., 2015, São Luiz, MA. Anais [...]. São 
Luiz: UFMA, 2015. Disponível em: http://www.joinpp.ufma.br/jornadas/joinpp2015/anaisjoinpp-2015.html. Acesso em: 20 abr. 2017.

SPOSATI, Aldaíza. Estudo da capacidade protetiva das famílias beneficiárias de programas federais de transferências de renda em regiões periféricas metropolitanas. Brasília: Ministério do Desenvolvimento Social e Combate à Fome, 2011.

SZYMANSKI, Heloísa. Viver em família como experiência de cuidado mútuo: desafios de um mundo em mudança. Serviço Social \& Sociedade, São Paulo, SP, ano 23, n. 71, p. 9-25, 2002. Edição especial: famílias.

Recebido em: $30 / 07 / 2019$

Aceito em: 19/03/2020 